\title{
Sphingosine Kinases are Involved in Macrophage NLRP3 Inflammasome Transcriptional Induction
}

\author{
Shahzad Nawaz Syed ${ }^{1}\left(\mathbb{D}\right.$, Andreas Weigert $^{1}{ }^{1(\mathbb{O}}$ and Bernhard Brüne ${ }^{1,2,3,4, *(\mathbb{C})}$ \\ 1 Institute of Biochemistry I, Faculty of Medicine, Goethe-University Frankfurt, 60590 Frankfurt, Germany; \\ syed@biochem.uni-frankfurt.de (S.N.S.); weigert@biochem.uni-frankfurt.de (A.W.) \\ 2 Project Group Translational Medicine and Pharmacology TMP, Fraunhofer Institute for Molecular Biology \\ and Applied Ecology, 60596 Frankfurt, Germany \\ 3 German Cancer Consortium (DKTK), Partner Site Frankfurt, 60590 Frankfurt, Germany \\ 4 Frankfurt Cancer Institute, Goethe-University Frankfurt, 60596 Frankfurt, Germany \\ * Correspondence: b.bruene@biochem.uni-frankfurt.de; Tel.: +49-69-6301-7424
}

Received: 9 June 2020; Accepted: 30 June 2020; Published: 2 July 2020

check for updates

\begin{abstract}
Recent studies suggested an important contribution of sphingosine-1-phospate (S1P) signaling via its specific receptors (S1PRs) in the production of pro-inflammatory mediators such as Interleukin (IL)-1 $\beta$ in cancer and inflammation. In an inflammation-driven cancer setting, we previously reported that myeloid S1PR1 signaling induces IL-1 $\beta$ production by enhancing NLRP3 (NOD-, LRR- and Pyrin Domain-Containing Protein 3) inflammasome activity. However, the autocrine role of S1P and enzymes acting on the S1P rheostat in myeloid cells are unknown. Using human and mouse macrophages with pharmacological or genetic intervention we explored the relative contribution of sphingosine kinases (SPHKs) in NLRP3 inflammasome activity regulation. We noticed redundancy in SPHK1 and SPHK2 activities towards macrophage NLRP3 inflammasome transcriptional induction and IL-1 $\beta$ secretion. However, pharmacological blockade of both kinases in unison completely abrogated NLRP3 inflammasome induction and IL-1 $\beta$ secretion. Interestingly, human and mouse macrophages demonstrate varied responses towards SPHKs inhibition and IL-1 $\beta$ secretion. Clinical datasets of renal cell carcinoma and psoriasis patients showed a positive correlation between enzymes affecting the S1P rheostat with NLRP3 inflammasome components expression, which corroborates our finding. Our data provide a better understanding on the role of SPHKs and de novo synthesized S1P in macrophage NLRP3 inflammasome activation.
\end{abstract}

Keywords: Macrophage; sphingosine-1-phosphate; NLRP3 inflammasomes; inflammation; IL-1 $\beta$; renal cell carcinoma; psoriasis

\section{Introduction}

Macrophages are dynamic and versatile players of sterile and smoldering inflammation, due to the fact that they can mount, control, as well terminate inflammation [1,2]. In an inflammatory setting, including cancer, macrophages can be primed and activated by a variety of damage-associated molecular patterns (DAMPs), including toll-like receptor (TLR) agonists such as HMGB1 or BD-2. These agonists are produced by injured or damaged cells, which provokes the secretion of interleukin-1 beta (IL-1 $\beta$ ) and IL-18, amongst others. The secretion of IL-1 $\beta$ from primed macrophages depends on the formation of a large molecular scaffold that contains cytosolic pattern recognition receptors, adaptor proteins, and caspase-1, altogether composing the inflammasome. The pattern recognition receptor NOD-like receptor pyrin domain containing 3 (NLRP3) is well characterized, most relevant to sterile inflammatory responses, and has been implicated in sensing non-microbial-originated DAMPs [3-6]. Any trigger that activates the transcription factor nuclear factor kappa B (NF-kB), such as ligands 
for IL-1R1, TLRs, NOD-like receptors (NLRs), and the cytokine receptors for tumor necrosis factor (TNFR) are considered as the priming stimuli, also known as "signal 1," for NLRP3 inflammasome activation $[7,8]$. Signal 1 is required for upregulating the transcription of both pro-IL-1 $\beta$ and NLRP3 since pro-IL-1 $\beta$ is not constitutively expressed and basal expression of NLRP3 is inadequate for efficient inflammasome formation [9]. The "signal 2" for inflammasome activation derives from a diverse group of agonists that trigger the specific activation of NLRP3, assembly of the inflammasome complex that requires its interaction with the pyrin domain of ASC (apoptosis-associated speck-like protein containing carboxy-terminal CARD; encoded by PYCARD), and finally culminates in the activation of caspase-1 $[7,10]$. Caspase- 1 then cleaves pro-IL-1 $\beta$ into its active form as a prerequisite of its release and activity at the IL- 1 receptor. IL-1 $\beta$ is a key inflammatory cytokine associated with many pathologies and is responsible for triggering multiple downstream inflammatory pathways [11]. We recently demonstrated that in tumor-associated macrophages NLRP3 inflammasome activation and subsequent IL-1 $\beta$ release is downstream of sphingosine-1-phosphate receptor 1 (S1PR1) signaling [12]. S1PR1 was also involved in promoting ATP release, at least in a murine macrophage cell line, which is one of the triggers of NLRP3 inflammasome activation [13]. Furthermore, the release of cathepsin B from lysosomes was associated with S1PR2 signaling [14] and the levels of IL-1 $\beta$ and IL-18 were reduced in serum of S1PR2-deficient mice challenged with endotoxin [15]. Thus, S1P via S1PR1/2 may cooperate toward NLRP3 inflammasome assembly and activation, promoting IL-1 $\beta$ maturation. However, if the inflammasome is also regulated at the level of S1P kinases is unknown.

Sphingosine-1-phosphate (S1P) is an important membrane derived, pleotropic signaling lipid that plays prominent roles in several diseases [16-19]. Especially in the context of inflammation, this lipid been shown to regulate various cellular events such as chemotaxis, apoptosis, phagocytosis, and macrophage polarization $[19,20]$. Intracellularly, S1P levels are dynamically regulated at picomolar concentrations by its synthesis and degradation by various enzymes, including sphingosine kinase (SPHKs), S1P lyases (SGPLs), and S1P phosphatases (SGPPs). S1P is generated from sphingosine by phosphorylation, which is carried out by two metabolically redundant kinases, i.e., SPHK1 and SPHK2. S1P binds to its specific G-protein-coupled receptors (S1PR1-S1PR5) to elicit cell responses. Besides, it can also bind to intracellular targets such as histone deacetylases and TNFR-associated factor 2 (TRAF2) [21,22]. Intracellular S1P can also act as a second messenger to trigger calcium release from the endoplasmic reticulum [23-25]. In spite of demarcated receptor-dependent and independent actions of $\mathrm{S1P}$, the autocrine and paracrine functions of S1P in innate immune cells such as macrophages are still elusive, especially in the context of NLRP3 inflammasome activation. Furthermore, factors upstream to S1PRs were not systematically investigated as a putative therapeutic targets in inflammation and cancer. In this study, we sought to characterize autocrine and paracrine functions of S1P in macrophages and to define components of S1P production or its signaling machinery that is best suited to target S1P-dependent NLRP3 inflammasome activation and IL-1 $\beta$ production.

\section{Results}

\subsection{Sphingosine Kinases are Involved in Signal 1 of NLRP3 Inflammasome Activation}

To investigate the relative contribution of SPHKs in autocrine and paracrine S1PR activation, subsequent NLRP3 inflammasome activation, and IL-1 $\beta$ maturation, we activated the NLRP3 inflammasome in primary human macrophages by priming them with lipopolysaccharides (LPS) in combination with the inflammasome assembler aluminum hydroxide (AlOH). NLRP3 activation was carried out in the presence of the SPHK1 selective inhibitor (CAY10621) [26], the SPHK1/ SPHK2 inhibitor (SKI-II) [27-29], an S1PR1 antagonist (W146) [12] and the S1PR1/S1PR3 antagonist (VPC 23019) [30]. Mature IL-1 $\beta$, released in the supernatant, was measured by the cytometric bead array (CBA), with a capture antibody that detects only mature IL-1 $\beta$, as a function of NLRP3 inflammasome activation (Figure 1A). SKI-II, which blocks both SPHKs, significantly reduced IL-1 $\beta$ levels in the cell supernatant. All other treatments, including the selective inhibition of SPHK1, failed to alter 
IL-1 $\beta$ levels. Interestingly, blocking both S1P kinases by SKI-II provoked a massive release of TNF- $\alpha$ (Figure 1B). Reduced levels of mature IL-1 $\beta$ could be ascribed to either reduced expression, reduced inflammasome activity, or both, since a fully active NLRP3 inflammasome requires "signal 1" to induce transcription and "signal 2" for inflammasome assembly [31] (Figure 1C). To decipher at which stage SPHKs interfere with NLRP3 inflammasome activation primary human macrophages were sequentially incubated for $30 \mathrm{~min}$ with SKI-II, followed by $4 \mathrm{~h}$ with LPS. Afterwards inflammasome assembly was triggered for $2 \mathrm{~h}$ with $\mathrm{AlOH}$ (Figure 1D). Blocking sphingosine kinases prior to "signal 1 " significantly reduced the release of mature IL-1 $\beta$, whereas interfering with S1P kinases after LPS stimulation and prior to or simultaneously with inflammasome assembly had no influence on IL-1 $\beta$ release (Figure 1D). Conclusively, sphingosine kinase activities may affect transcriptional responses of the inflammasome in macrophages. To test this hypothesis, we measured expression kinetics of NLRP3 inflammasome components in the presence of SKI-II. As shown in Figure 2A, NLRP3 expression was significantly reduced when macrophages were treated with SKI-II and expression of IL1B was attenuated as well (Figure 2B). However, SKI-II treatment had no influence on TNFA expression (Figure 2C). These results imply that indeed SPHKs activity can be linked to the transcription of NRLP3 inflammasome component.
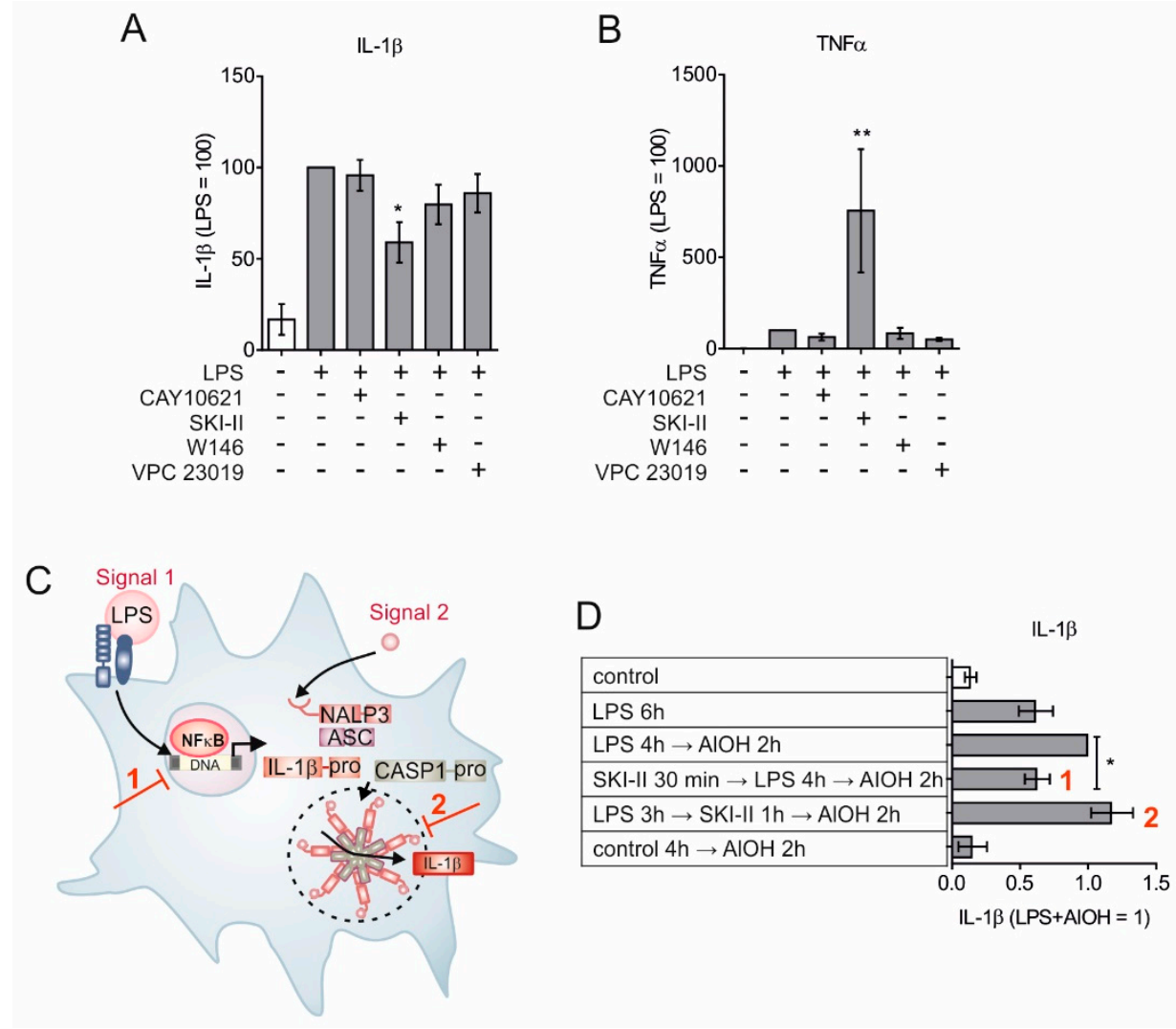

Figure 1. Sphingosine kinases are involved in "signal 1" of the NLRP3 inflammasome. Primary human macrophages were preincubated for 30 min with $5 \mu \mathrm{M}$ CAY10621, $10 \mu \mathrm{M}$ SKI-II, and $1 \mu \mathrm{M}$ each of W146 and VPC 23019. Cells were then stimulated with $10 \mathrm{ng} / \mathrm{mL}$ LPS with or without inhibitors for $2 \mathrm{~h}$. Agonists and inhibitors were washed off and cells were further cultivated in fresh media for another $24 \mathrm{~h}$. Cell free supernatants were analyzed for (A) IL-1 $\beta$ and (B) TNF- $\alpha$ by cytometric bead array (CBA). Data are means $\pm \mathrm{SEM}, n=6$ donors. (C) Schematic depiction of two signals for NLRP3 inflammasome activation. Red numbers indicate intervention with signal 1 and signal 2 respectively. (D) Macrophages were left untreated, treated with $100 \mathrm{ng} / \mathrm{mL}$ LPS, $1 \mu \mathrm{g} / \mathrm{mL}$ AlOH and $10 \mu \mathrm{M} \mathrm{SKI-II}$ for $1-6 \mathrm{~h}$ in a permutation and combination depicted in the table and IL- $1 \beta$ levels were measured in cell-free supernatant using CBA. Red numbers indicated interventions as depicted in C. Data are means \pm SEM, $n \geq 10$ donors. ${ }^{*} p<0.05 ;{ }^{* *} p<0.001 ; p$ values were calculated using one-sample $t$ test $(\mathbf{A}, \mathbf{C}, \mathbf{D})$. 
A

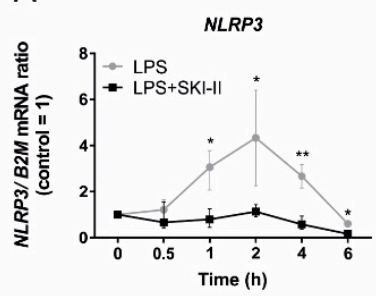

D

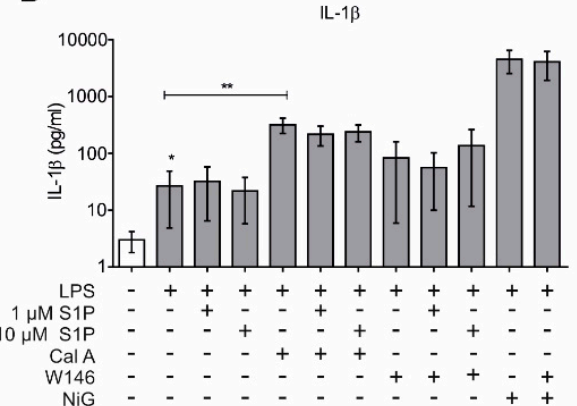

B

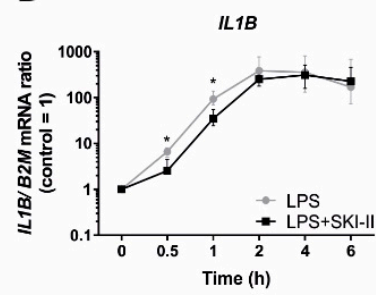

C

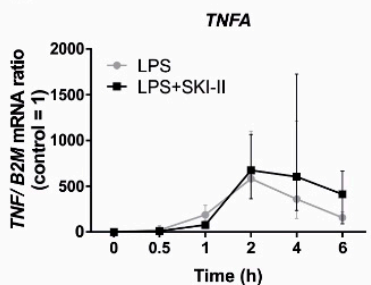

TNF $\alpha$

E

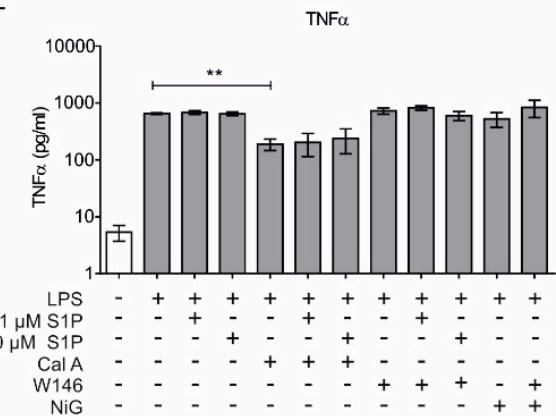

Figure 2. S1P kinases affect transcription of inflammasome components, without showing paracrine effects. (A-C) Primary human macrophages were pre-incubated with $10 \mu \mathrm{M}$ SKI-II for 30 min then stimulated with $100 \mathrm{ng} / \mathrm{mL}$ LPS for up to $6 \mathrm{~h}$. Samples were harvested at different time points as presented on $\mathrm{X}$-axis and gene expression was analyzed by qPCR of (A) NLRP3, (B) IL-1 $\beta$ and (C) TNF- $\alpha$. Data are means \pm SEM, $n \geq 5$ donors for each time points. (D, E) Cells were stimulated for $4 \mathrm{~h}$ with $500 \mathrm{ng} / \mathrm{mL}$ LPS. After washing LPS, cells were treated for $20 \mathrm{~min}$ with $25 \mathrm{nM}$ calyculin A or $1 \mu \mathrm{M}$ W146. Cells were again washed and treated for $2 \mathrm{~h}$ with $25 \mathrm{nM}$ calyculin A, $1 \mu \mathrm{M} \mathrm{W146,} 1$ and 10 $\mu \mathrm{M}$ S1P. Afterward, $6.7 \mu \mathrm{M}$ nigericin was added for final $30 \mathrm{~min}$. Cell-free supernatant containing (D) IL-1 $\beta$ and (E) TNF- $\alpha$ in last $2 \mathrm{~h}$ of treatments were measured by CBA. Data are means \pm SEM, $n \geq 6$ donors. ${ }^{*} p<0.05 ;{ }^{* *} p<0.001 ; p$ values were calculated using two-tailed Student's $t$-test.

The above findings so far did not fully rule out the involvement of S1P as a signal 2 for NLRP3 inflammasome activation and there are reports that at least sphingosine can fulfill this role [32,33]. To further investigate a potential role of a paracrine S1P action on the NLRP3 inflammasome activation, primary human macrophages were treated for inflammasome activation (LPS and AlOH), while S1P was exogenously provided. IL- $\beta$ secretion was not potentiated with exogenous S1P even at a $10 \mu \mathrm{M}$ concentration, which surpasses the concentration required to activate S1P receptors (Figure 2D). Furthermore, FTY720 a structural analogue of S1P that gets phosphorylated by sphingosine kinases to resemble S1P, is known to increase the activity of phosphatase PP2A, which is being implicated in inflammasome activation [32,34]. However, unlike mouse macrophages [32], human macrophages did not show any response to calyculin $\mathrm{A}$, a serine/threonine phosphatase (PP1/PP2A) inhibitor, which failed to reduce IL-1 $\beta$ secretion. On the contrary, PP1/PP2A inhibition enhanced IL-1 $\beta$ release, with no impact of exogenous S1P supplementation (Figure 2D). We also ruled the role of exogenous S1P in NLRP3 inflammasome activation out, by probing S1P signaling in potassium efflux, which emerged as a common denominator in the both canonical $[35,36]$ and non-canonical $[37,38]$ NLRP3 inflammasome activation. Treatment with the potassium ionophore nigericin $(6.7 \mu \mathrm{M})$ for $30 \mathrm{~min}$ after LPS stimulation provoked a massive release of mature IL-1 $\beta$, which was unaffected by blocking autocrine signaling of S1P using $1 \mu \mathrm{M}$ of the S1PR1 antagonist W146 (Figure 2D). ATP-mediated NLRP3 inflammasome activation [4] was also unaffected by exogenous S1P or S1PR1 blockage (data not shown). As expected, PP1/PP2A inhibition revealed anti-inflammatory effects in macrophages as TNF- $\alpha$ secretion upon LPS-stimulation was reduced (Figure 2E). At the same time, data in Figure 2E suggest that the compounds used in Figure 2D have no major side effects in terms of their inflammatory potential in human macrophages as the levels of TNF $\alpha$ with these treatments were comparable. 
Together, these data indicate that the activities of both, SPHK1 and SPHK2 are affecting the expression of NLRP3 inflammasome components without auto/ or paracrine activation of S1PRs.

\subsection{Sphk1 and Sphk2 Redundancy for Mouse Macrophage Nlpr3 Inflammasome Expression}

We then tried to delineate the relevance of individual S1P kinases by using bone marrow-derived macrophages (BMDM) from B6 wild type mice (WT) and mice deficient in Sphk1, Sphk2 and S1pr1, for analyzing the expression of NLRP3 inflammasome components. LPS strongly induced Il1b expression in BMDMs of all mouse strains, however there was a significant reduction in $I l 1 b$ expression in Sphk1 and Sphk2 deficient cells (Figure 3A). When the release of mature IL-1 $\beta$ from these cells was measured by CBA, S1pr1 and SphK2 deficient cells showed a lower IL-1 $\beta$ release (Figure 3B). The cytokine IL-18 also depends on NLRP3 inflammasome activity for maturation but showed week expression compared to Il1b. However, Sphk2 deficiency potentiated its expression upon LPS stimulation (Figure 3C). Expression of the inflammasome component Nlrp3 was drastically enhanced without significant differences among individual mouse strains (Figure 3D), whereas expression of caspase-1 (Casp1) was significantly upregulated only in S1pr1 deficient macrophages (Figure 3E). Pycard (also known as ASC), a subunit of inflammasome, was downregulated upon LPS stimulation in cells of all strains (Figure 3D).

A

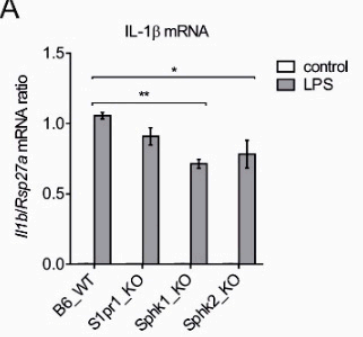

D

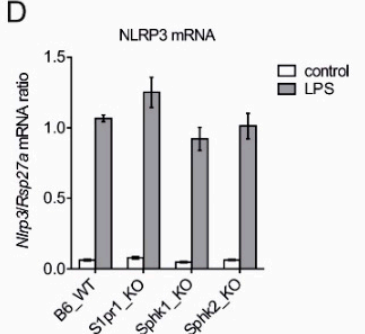

B

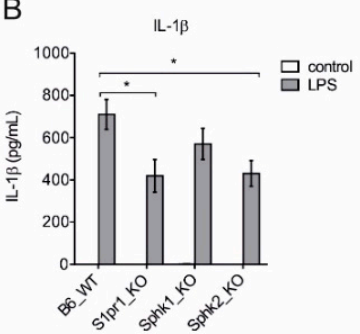

E

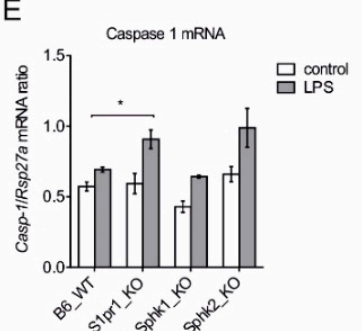

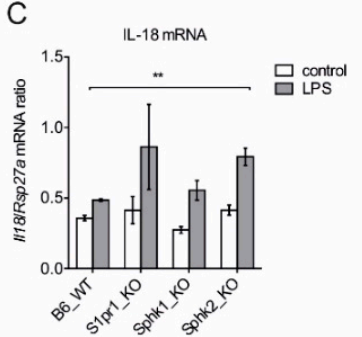

$\mathrm{F}$

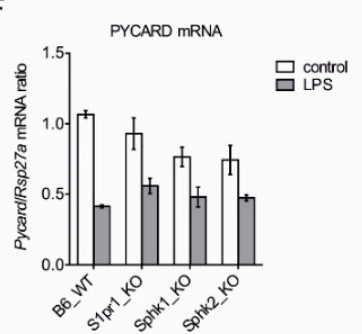

Figure 3. Relative contribution of Sphk1, Sphk2, and S1pr1 in the expression of individual NLRP3 inflammasome components. BMDMs from B6 WT, S1pr1-LysM-Cre mice, Sphk1 KO, and Sphk2 KO mice were stimulated with $100 \mathrm{ng} / \mathrm{mL}$ LPS for $3 \mathrm{~h}$ before mRNA expression analysis by qPCR.. mRNA expression of (A) Il1b, (B) determination of mature IL-1 $\beta$ release by CBA after $7 \mathrm{~h}$, (C) Il18, (D) Nlpr3, (E) Casp1 and (F) Pycard expression was analyzed. Data are means \pm SEM, $n \geq 4$ mice. ${ }^{*} p<0.05$; ${ }^{* *} p<0.001 ; p$ values were calculated using two-tailed Student's $t$-test.

These data suggest that SPHKs play a role in the transcription of Il1b, whereas S1PR1 signaling might play a role in NLRP3 inflammasome activation.

\subsection{Role of S1PR1 in NLRP3 Inflammasome Activation and Cytokines/Chemokine Production}

Although exogenous S1P was not potent enough to trigger the NLRP3 inflammasome in primary human macrophages upon LPS stimulation in the absence of signal 2 (Figure 2D), mouse macrophages have been shown to respond differently to these stimuli [39,40]. Still, the role of S1PR1 as a signal 2 during NLRP3 inflammasome activation is unknown. We explored the relevance of S1PR1 in NLRP3 inflammasome activation using BMDMs from myeloid-specific S1PR1-ablated mice. B6 WT and S1PR1 $\mathrm{KO}$ macrophages were treated with LPS alone or in combination with $\mathrm{IFN} \gamma, \mathrm{AlOH}$, and imiquimod (IMQ). The release of cytokines and CCL5 was measured in the cell-free supernatant by CBA. LPS 
induced the secretion of mature IL-1 $\beta$, whereas IMQ produced only an insignificant release. However, NLRP3 signal 2 i.e., AlOH provoked much higher IL-1 $\beta$ secretion over LPS alone. S1PR1 deficient macrophages produced significantly lower amounts of mature IL-1 $\beta$ compared to WT controls (WT: $16,113 \pm 1441$ vs. S1PR1 KO: $10,247 \pm 1628 \mathrm{pg} / \mathrm{mL}$ ) (Figure $4 \mathrm{~A}$ ). To test if the attenuated response was specific to a particulate assembler such as $\mathrm{AlOH}$ or resembled a general phenomenon, we used the TL7 agonist IMQ as signal 2 for NLRP3 inflammasome activation, which has previously been described for murine macrophages [41,42]. IMQ alone fail to elicit any response from macrophages. However, similar to the $\mathrm{AlOH}$, we observed an attenuated response in S1PR1 KO macrophages when IMQ was used as an assembler of the NLRP3 inflammasome in combination of LPS (WT: 11,793 \pm 2359 vs. S1PR1 KO: $7636 \pm 3170 \mathrm{pg} / \mathrm{mL}$ ) (Figure 4A). This suggested that S1PR1 signaling might regulate NLRP3 inflammasome in a broader sense. We also measured cytokines such as IL-6 (Figure 4B), IL-10 (Figure 4C), and IL-23 (p19/p40) (Figure 4D) as well as the chemokine CCL5 (Figure 4E). Interestingly, S1PR1 KO cells do not differ from WT in any treatment for these factors, except IL-6, which was attenuated in S1PR1 KO macrophages upon LPS stimulation (Figure 4B).

A

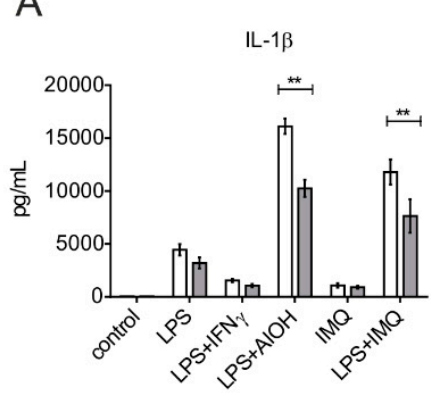

B

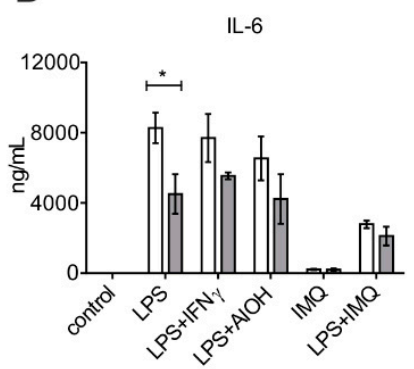

C

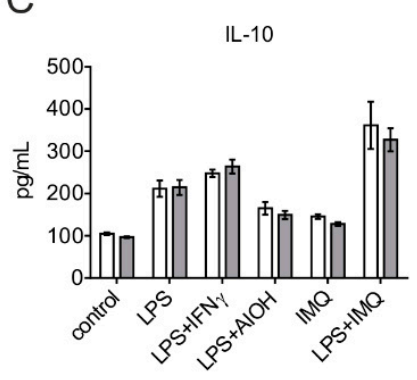

$E$

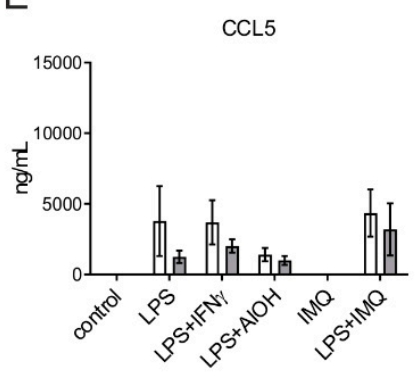

Figure 4. Role of S1PR1 in NLRP3 inflammasome activation. WT and S1PR1 KO macrophages (BMDMs) were treated with $100 \mathrm{ng} / \mathrm{mL}$ of LPS and IFN $\gamma$ each, $10 \mu \mathrm{g} / \mathrm{mL}$ IMQ and $100 \mu \mathrm{g} / \mathrm{mL}$ AlOH for $16 \mathrm{~h}$. Cell-free supernatants were harvested and analyzed by CBA for (A) IL-1 $\beta$, (B) IL-6, (C) IL-10, (D) IL-23 (p19/p40) and (E) CCL5. Data are means \pm SEM, $n=4$ mice. ${ }^{*} p<0.05 ;{ }^{* *} p<0.001 ; p$ values were calculated using two-way ANOVA with Sidak correction.

In these experimental conditions, data from S1PR1 KO macrophages suggest that S1PR1 signaling specifically alters NLRP3 inflammasome activation without major effects on other effector functions of macrophages such as cytokine and chemokine production.

\subsection{Redundant Role of SPHK1 and SPHK2 in NLRP3 Inflammasome Activation}

Next, we wanted to assign a role to each S1P kinases in NLRP3 inflammasome activation in macrophages. Hence, to dissect the role of SPHK1 and SPHK2 in macrophage inflammasome activation, we compared B6 WT with Sphk1 KO and Sphk2 KO macrophages during NLRP3 inflammasome activation. When both signals for NLRP3 inflammasome activation were present, i.e., LPS and AlOH, IL-1 $\beta$ release was again greatly enhanced compared to priming with LPS alone (Figure 5A,B). Genetic deletion of individual S1P kinases showed limited effect on IL- $\beta$ secretion as both Sphk1 or Sphk2 KO 
macrophages produced comparable amount of IL-1 $\beta$ (Figure 5B). However, mimicking the kinase double KO condition by using the SKI-II inhibitor, NLRP3 inflammasome activity was completely abrogated as only negligible amounts of IL-1 $\beta$ were released from Sphk1 or Sphk2 KO macrophages (Figure 5B). We also measured IL-6 release from these macrophages. SPHKs were also required for IL-6 production upon LPS stimulation. Genetic deletion of Sphk2 or pharmacological blockage of SPHK1 and SPHK2 significantly reduced IL-6 production (Figure 5C). In contrast, TNF- $\alpha$ secretion was largely intact in SPHK KO macrophages, while SKI-II even enhanced TNF- $\alpha$ release in all groups (Figure 5D).
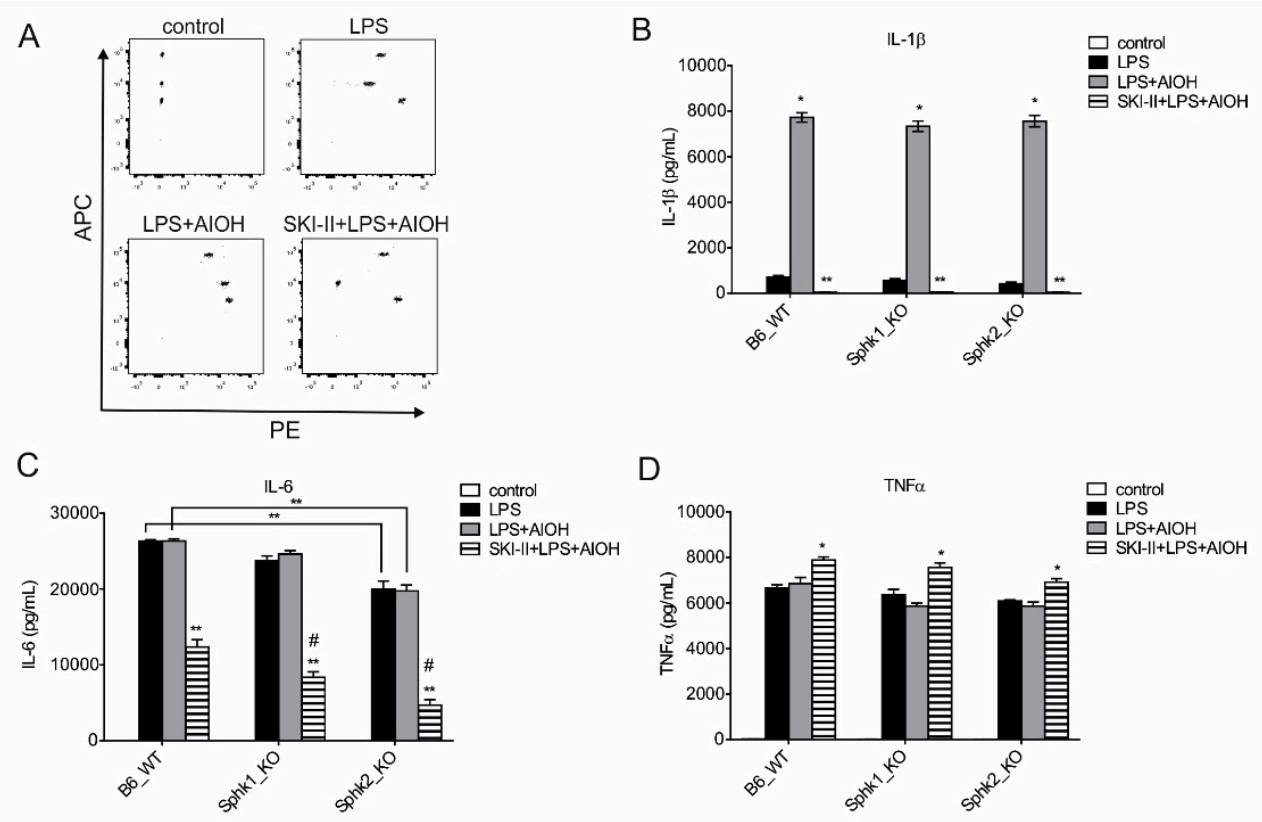

Figure 5. Individual SPHKs are redundant in NLRP3 inflammasome activation. Bone marrow-derived macrophages (BMDMs) from B6 WT, Sphk1 KO, and Sphk2 KO were stimulated with LPS alone or in combination with $10 \mu \mathrm{M}$ SKI-II, $10 \mu \mathrm{g} / \mathrm{mL}$ IMQ, and $100 \mu \mathrm{g} / \mathrm{mL}$ AlOH for $24 \mathrm{~h}$. Cell-free supernatants were harvested and analyzed by CBA. (A) Representative FACS dot-plot of phycoerythrin (PE) and allophycocyanine (APC), (B) IL-1 $\beta$, (C) IL-6 and (D) TNF- $\alpha$ level. Data are means \pm SEM, $n \geq 4$ mice. \#, significant to $\mathrm{B} 6 \mathrm{WT} ;{ }^{*} p<0.05 ;{ }^{* *} p<0.001 ; p$ values were calculated using two-way ANOVA with Sidak correction.

These data highlight the contribution of both SPHK1 and SPHK2 to NLRP3 inflammasome activation and IL-6 production in mouse macrophages.

\subsection{Clinical Correlation of SPHKs and NLRP3 Inflammasome Expression}

Finally, to understand the clinical relevance of our finding, we analyzed expression pattern of these genes in an inflammatory condition and a cancer type where both S1P and macrophages have been reported in poor prognosis [43-46]. We analyzed publicly available datasets of patients comprising 535 tumor samples and 72 control tissue of clear cell renal cell carcinoma [47]. Expression data of genes in cancer and corresponding normal tissues were downloaded from the TCGA-KIRC project [47] via the Genomic Data Commons Data Portal [48] and curated by ENCORI Pan-Cancer Analysis Platform [49]. There was a significantly enhanced expression of SPHK1 in cancer tissue compared to normal tissue (Figure 6A). The expression of SPHK2 and SGPL1 were downregulated in cancer compared to normal tissue (Figure $6 \mathrm{~B}, \mathrm{C}$ ). NLRP3 and IL1B were upregulated in cancer tissue compared to normal (Figure 6D,E), while IL6 expression was unaltered (Figure 6F). Next, we analyzed expression datasets in an inflammatory skin condition, i.e., psoriasis [50,51]. A high throughput sequencing dataset (GSE54456) containing 92 psoriatic and 82 normal skin samples was downloaded from Gene Expression Omnibus (GEO). An in silico S1P production ratio was generated by comparing mean 
expression of S1P generating, versus S1P degrading enzymes (mean expression (SPHK1 + SPHK2) / mean expression (SGPL1) and compared with NLRP3 inflammasome components (IL1B, NLRP3, PYCARD, and CASP1) and NF-kB target genes (IL6, NFKBIA, XIAP, TRAF2, and HIF1A). Apparently a high S1P ratio, which may indicate increased S1P levels, was positively correlated with NLRP3 inflammasome components, except CASP1, which corroborated our findings (Figure 6G,H). In contrast, NF- $\mathrm{KB}$ target genes presented a mosaic picture in which TRAF2 and NFKBIA positively correlated and XIAP and HIF1A negatively correlated with the S1P ratio (Figure $6 \mathrm{G}, \mathrm{H}$ ).

A

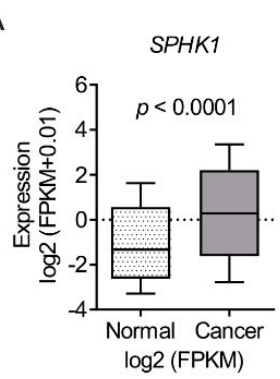

$\mathrm{D}$

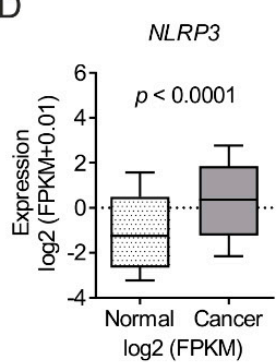

B

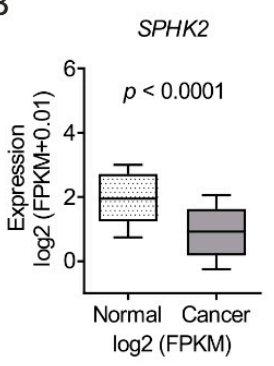

E

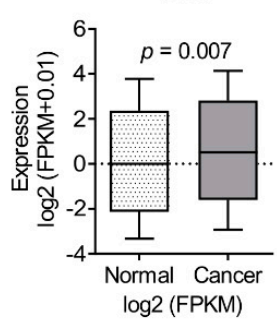

C

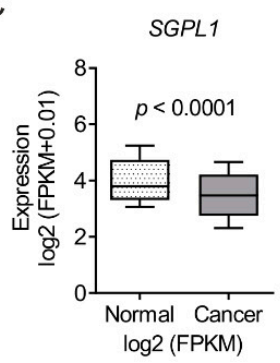

$\mathrm{F}$

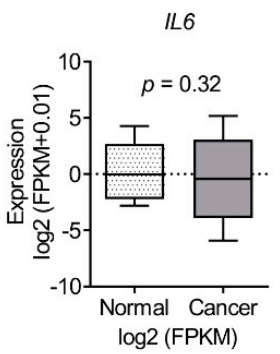

G

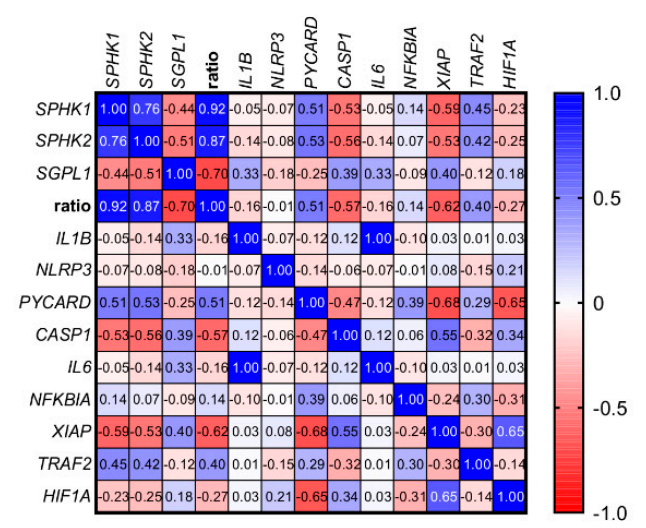

$\mathrm{H}$

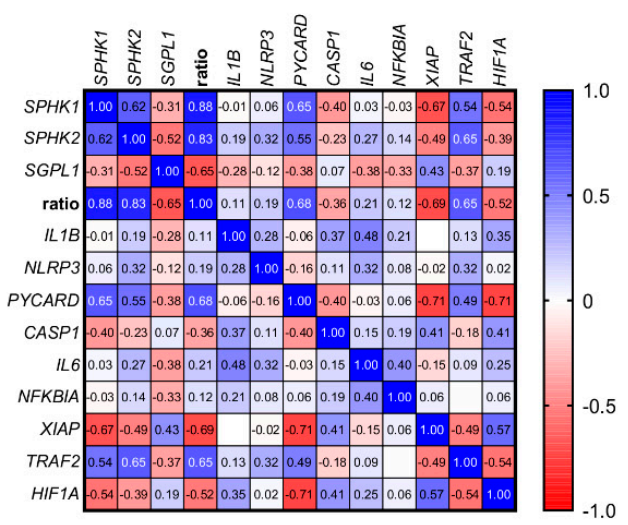

Figure 6. Clinical correlation between SPHKs and NLRP3. The expression of S1P metabolizing enzymes were correlated with that of NLRP3 inflammasome components in kidney renal cell carcinoma and psoriatic skin. Publicly available TCGA-KIRC datasets of cancer and normal adjacent tissue were analyzed for the expression of (A) SPHK1, (B) SPHK2, (C) SGPL1, (D) NLRP3, (E) IL1B and (F) IL6 from tumor (cancer; $n=535$ ) and normal (normal; $n=72$ ) samples. Results are presented as $\log 2$ fragments per kilobase of transcript per million mapped reads (FPKM). Gene expression data in Gene Expression Omnibus (GEO) dataset GSE54456 comprising of (G) normal skin ( $n=82$ and (H) psoriatic skin $(n=92)$ were analyzed for NLRP3 inflammasome components (IL1B, NLRP3, PYCARD and CASP1) and NF-KB target genes (IL6, NFKBIA, XIAP, TRAF2 and HIF1A) with an in silico generated S1P production ratio. Spearman $r$-values are indicated. $P$ values were calculated using two-tailed Student's $t$-test. 
The above datasets suggested a net S1P production due to enhanced expression of cytosolic S1P synthesizing enzyme (SPHK1) vs. S1P degrading enzyme (SGPL1). This net S1P production was corelated with enhanced expression of NLRP3 inflammasome components (NLRP3, IL1B). These clinical datasets corroborated our finding of a positive correlation between SPHKs expression and NLRP3 inflammasome components in macrophages.

\section{Discussion}

S1P plays an important role in several inflammatory diseases including inflammation-driven cancers. Therefore, enzymes required for S1P metabolism inadvertently became attractive therapy targets for these diseases. Steady state levels of S1P are controlled not only by S1P biosynthetic enzymes (SPHKs) but also by S1P degradative pathways, such as a S1P-specific lyase (SPGL) and by three lipid phosphatases. The net activity of these enzymes controls the S1P rheostat. In order to understand and assign a pharmacological relevance to S1P metabolic enzymes, we deciphered the role of S1P, upstream of S1PRs, in NLRP3 inflammasome activation and inflammation with the assumption that SPHKs might play an important role in this process. SPHK1 and SPHK2 have overlapping characteristic functions but also differ in their function and localization [52]. The predominant location of SPHK1 is in the cytoplasm, from where it rapidly translocates to the plasma membrane upon stimulation. SPHK1 activity, therefore, leads to "inside-out" S1P signaling in an autocrine and/or paracrine fashion $[17,53,54]$. S1PR1 can be activated via lateral slide of S1P within the plane of the membrane bilayer to access the receptor binding pocket for activation [55], suggesting that S1P may not be required to be secreted for its autocrine action and S1PR1 blockage. This may explain why W146 may not prevent SPHKs-derived S1P action towards NLRP3 inflammasome (Figures 1A and 2D). However, the release of NF- $\mathrm{KB}$ target gene product such as IL-1 $\beta$ and IL-6 was reduced in S1PR1 KO macrophages (Figure 4A,B). This may suggest a role of S1PR1 in NF-kB signaling. Moreover, SPHK1 can also interacts with TRAF2 that causes NF- $\mathrm{KB}$ activation [56], which is also a converging point of TLR4 activation by LPS. This supports the idea that SPHK1 may cooperate with TLR4 signaling in inflammatory responses independent of S1PR signaling and S1P production. Furthermore, S1P can also trigger a positive feedback amplification loop via S1PRs activation that increases SPHK1 expression [57], which may also explain increased expression of NLRP3 and IL1B in human macrophages (Figure 2A,B). Noteworthy, it has already been shown that LPS stimulated macrophages produce S1P, which acts as an intracellular secondary messenger rather than an extracellular ligand for S1PRs [58,59]. Furthermore, LPS per se increases NALP3 protein stability without significantly altering steady-state mRNA by degrading its negative regulator F-box protein FBXL2 in human monocytes [60]. SPHK2, on the other hand, can shuttle in and out of the nucleus, due to the presence of nuclear localization and nuclear export signal, and primarily resides at the endoplasmic reticulum [61,62]. S1P generated via SPHK2 can affect cell survival and growth $[21,62,63]$. Our data provide additional information to SPHK2 and cell survival as Sphk2 KO macrophages produced reduced amount of IL-6 (Figure 5C), which is also being implicated in cell survival by polarizing cells towards alternatively activated macrophages by HIF-1 $\alpha$ activation and upregulation of anti-apoptotic proteins [64-66]. We have recently reported that inflammatory stimulated human macrophages show a biphasic response to SPHK2 expression and activity. Of note SPHK2 activity is required for an early inflammatory activity and to dampen late inflammatory responses [67]. We observed that SPHK2 was degraded upon LPS-treatment, which was necessary to allow the full magnitude of early inflammatory cytokine production from human macrophages [67]. These kinetic attributes of SPHK2 might explain the induction of TNF- $\alpha$, though to a varying degree in human (Figure 1B) and mouse (Figure 5D) macrophages and upon blockage with SKI-II. SPHK2 can also binds to histone H3 in the nucleus and bring about epigenetic regulation of gene expression by nuclear S1P action on histone deacetylases [21]. How and if epigenetic regulations mediated by SPHK2 are also linked to NLRP3 inflammasome activity and inflammation is currently unknown and requires further investigation. 
TLR4 activation, or any signal that activates NF- $\mathrm{KB}$, primes NLRP3 inflammasome. Recent studies suggested that LPS not only activates TLR4 signaling but also the hexa-acyl lipid A component of LPS is able to access the cytoplasm, where it activates caspase-11 to signal NLRP3 inflammasome activation independently of TLR4 [68,69]. There are several activators for NLRP3 such as ROS, mitochondrial dysfunction, lysosomal leakage, changes in cellular calcium flux, membrane pore formation, and potassium efflux. Potassium release is found in association with all NLRP3 activators and apparently a culture medium low in potassium is sufficient to trigger NLRP3 activation. [35]. Imiquimod, a TLR7 agonist, can induce the NLRP3 inflammasome independent of potassium using NEK7 as a ROS sensor [41]. Intriguingly, IMQ enhances the anti-inflammatory potential of mouse macrophages by potentiating IL-10 release (Figure 4C). Unlike in mouse cells, IMQ does not act as a signal 2 for NLRP3 inflammasome activation in primary human macrophages. These differences might be due to intrinsic variances between human and mouse NLRP3 inflammasome activation [70] or might be due to cooperation of S1PRs signaling with TLR4 and TLR7, which is a contention of further investigation.

There is redundancy in the action of SPHK1 and SPKH2 in terms of NLRP3 inflammasome activation as activity of either of these enzymes restored NLRP3 activity (Figure 5B). This redundancy could also be due to various factors including expression regulation of individual NLRP3 components since Sphk1 deficiency attenuate Il1b expression (Figure 3A), whereas NLRP3 activity was unaltered (Figures $3 \mathrm{~B}$ and $5 \mathrm{~B}$ ). However, the functional redundancy is not new for these kinases as it has been reported in the literature that mice lacking either Sphk1 or Sphk2 are viable, fertile and have no obvious abnormality [71,72]. In contrast double knockout show prenatal death, owing to severe defects in neurogenesis and angiogenesis [72]. Furthermore, compensatory upregulation of Sphk1 expression was observed in Sphk2 deficient macrophages [73].

SPHKs not only catalyze similar enzymatic reaction to produce anti-apoptotic S1P, while consuming pro-apoptotic ceramide, they show interdependence on each other in S1P signaling even in pharmacological settings. For example fingolimod (FTY720), one of the widely used pharmacological compounds for antagonizing S1PR1, is processed by SPHK2 to fingolimod-phosphate, which serves as a potent agonist of S1PR1 [74,75] as well as an inhibitor of SPHK1 [76]. Since most S1P actions are mediated by S1PRs, currently, the major class of drugs interfering with S1P signaling are directed towards S1PRs rather than metabolic enzymes involved in S1P biosynthesis/processing. There is no question that targeting a specific S1PR would provide selectivity with some off-target effects. Pharmacologically, targeting enzymes is more potent due to high specificity and does not pose a threat of target activation, which is an issue when targeting $G$ protein-coupled receptors such as S1PRs. For example, fingolimod has been shown to be a potent agonist of S1PR1. However, on lymphocytes, fingolimod can downregulate S1PR1, thus preventing the egress of these cells from lymphoid tissues. This dichotomy (agonism/antagonism) of fingolimod on S1PR1 reduces the infiltration of lymphocytes into the central nervous system, thereby blocking their undesirable effects $[74,77,78]$. Evidently, there are several options in terms of the nature of enzyme inhibitor such as competitive, non-competitive, uncompetitive and irreversible inhibitors that can be designed and used for optimal efficacy and in a specific scenario. The present study, describing the useful contribution of SPHKs in inflammasome assembly/activation, is a primer in this direction.

Taking an extra stride towards translation research, we used both human and mouse cells. We exploited both genetic deletion and pharmacological blockade of SPHK1 and SPHK2. One of the reasons of using genetically deleted SPHK1 and SPHK2 macrophages, in combination/addition to pharmacological inhibitors, was to avoid side effects reported for pharmacological inhibitors. Conversely, the genetic deletion of Sphk2 showed minor effects on disease progression in the mouse model of TNF- $\alpha$-induced arthritis, whereas the pharmacologic inhibition with the SPHK2 inhibitor ABC294640 augmented disease severity [79]. Nevertheless, while SKI-II exhibits no inhibitory action on other kinases including PI3K, PKC $\alpha$ and ERK2 [27,80-82], side effects of SKI-II cannot be ruled out since Sphk1 and Sphk2 double KO macrophages have been shown to have redundant pro-inflammatory responses to LPS [73]. Furthermore, our experimental conditions do not rule 
out effects of upstream metabolites i.e., ceramide accumulation due to attenuated SPHK activities. It was shown that a lipotoxicity-associated increase of ceramide provokes caspase- 1 cleavage and NLRP3 inflammasome activation in macrophages and adipose tissue [83], suggesting that the NLRP3 inflammasome can sense elevated intracellular ceramide. Furthermore, age-related increased thymic ceramides also support NLRP3 inflammasome-dependent caspase-1 activation [84]. Nevertheless, these studies also serendipitously support our findings and underscore the role of SPHKs in NLRP3 inflammasome activation.

Monocytes and macrophages are critical players psoriasiform skin inflammation $[43,85]$ and in the tumor microenvironment [44], and they are being implicated to play tumor-promoting roles in human renal cell carcinoma (RCC) patients. Expectedly, IL1B expression was enhanced in blood monocytes isolated from RCC patients [86] and in tumor tissue (Figure 6E). SGPL1 expression was also downregulated in RCC tumor samples (Figure 6C), which supports our narrative. However, the precise role of this enzyme in cancer has not been established yet as its expression was reduced in intestinal cancer [87] and metastatic tumors [88], whereas increased in ovarian cancer [89] and in chemotherapeutic resistant ovarian tumors [90]. SPHK2 seem to be downregulated in RCC tumors (Figure 6B), which goes in line with studies suggesting that although both SPHK1 and SPHK2 use the same physiologic substrate and generate S1P, SPHK2 might have a role opposite to that of SPHK1 as over-expression of SPHK2 suppresses cell growth and enhances apoptosis [61,91]. Furthermore, the expression profile of SPHK2 and IL6 in human RCC tumors correlated with the finding of mouse macrophages (Figure 5C), suggesting that the role of this kinase in IL-6 production has pathophysiological relevance. SPHK1 overexpression contributes to sunitinib resistance in clear cell renal cell carcinoma [92]. In spite of a positive correlation between the S1P metabolic enzymes and inflammation in RCC, globally targeting S1P using the anti-S1P monoclonal antibody sonepcizumab failed in a phase II clinical trial of metastatic renal cell carcinoma [45]. On the other hand, hispidulin, a polyphenolic flavonoid, suppressed tumor growth and metastasis of RCC cells by interfering with the phosphorylation and translocation of SPHK1, thereby inhibiting its activity without affecting mRNA or protein expression [93].

Being an inflammatory dermatosis, psoriasis shows hallmark feature of inflammation including elevated levels of active, phosphorylated NF- $\mathrm{kB}$. NF- $\mathrm{kB}$ has been hypothesized to connect the altered keratinocyte and immune cell behavior that characterizes the psoriatic milieu. Indeed, recent evidence suggests that the activation of particular NF- $\mathrm{kB}$ target genes is highly complex and dependent on selective gene regulation in distinct pathological settings [94]. Similarly, we noted that in psoriatic skin though there was a positive correlation with SPHKs and NLRP3 inflammasome components, some of the them are targets of NF- $\mathrm{KB}$ signaling. Other NF- $\mathrm{kB}$ target genes showed mosaic picture, both in healthy and psoriatic skin, indicating that regulation of NLRP3 inflammasome components might involve other signaling pathways than NF- $\mathrm{kB}$ alone (Figure $6 \mathrm{G}, \mathrm{H}$ ). Indeed, the exact molecular mechanisms how SPHKs affect NF-KB signaling in macrophage is still not fully understood and may require further detailed investigation.

In conclusion, we provide compelling, new evidence for a direct involvement of SPHKs in macrophage NLRP3 inflammasome activation and provide a rationale for therapeutic targeting these kinases in cancer and inflammation.

\section{Materials and Methods}

\subsection{Mice and Reagents}

S1pr1 KO (S1pr1 $\left.{ }^{f l f l} L y z 2^{\mathrm{Cre} / \mathrm{Cre}}\right)$ and corresponding WT (S1pr1 $\left.{ }^{f l f l} \mathrm{Lyz} 2^{\mathrm{Cre} / w \mathrm{t}}\right)$ on C57BL/6 background have been described before [46]. Sphk1 KO [95,96] and Sphk2 KO [12,97] from Novartis were described before and were backcrossed for at least 10 generations into a C57BL/6 background. Mice were kept under standard pathogen-free conditions with ad libitum food (regular chow diet) and water, and a 12:12 h light:dark cycle. Organ removal and animal care were performed in accordance with the EU Directive 86/609 EEC and German Protection of Animals Act. No additional animal ethics 
approval is needed for organ removal for subsequent isolation of primary murine cells. Ultrapure lipopolysaccharide (LPS) from E. coli 0111:B4 was purchased from InvivoGen (San Diego, CA, USA), SKI-II (4-[[4-(4-chlorophenyl)-2-thiazolyl]amino]-phenol), CAY 10621 (2,2-dimethyl-4S-(1-oxo-2hexadecyn-1-yl)-1,1-dimethylethyl ester-3-oxazolidinecarboxylic acid), VPC 23019 ((R)-2-amino-3((3-octylphenyl)amino)-3-oxopropyl dihydrogen phosphate) were bought from Cayman Chemical (Ann Arbor, MI, USA), W146 (R-3-amino-4-(3-hexylphenylamino)-4-oxobutylphosphonic acid hydrate) and DMSO was purchased from Sigma-Aldrich (München, Germany). The source of all other reagents was mentioned at their respective use.

\subsection{RNA isolation, Reverse Transcription, and Quantitative Real-Time PCR}

Macrophages were snap frozen in liquid nitrogen or lysed directly in PeqGold ${ }^{\circledR}$ (Peqlab Biotechnology, Erlangen, Germany). Isolation of RNA from cells was performed according to the manufacturer's instructions and quantified using the NanoDrop spectrophotometer (NanoDrop, Wilmington, DE, USA). RNA was transcribed into cDNA for mRNA analysis using the Fermentas reverse transcriptase kit (ThermoFisher Scientific, Karlsruhe, Germany) according to the manufacturer's instructions. Real-time quantitative PCR (qPCR) was performed using the SYBR green on CFX96 ${ }^{\mathrm{TM}}$ Real-Time PCR Detection System (Bio-Rad Laboratories, Munich, Germany) and the QuantStudio 5 Real-Time PCR System (Applied Biosystems, Damstadt, Germany). QuantiTect primer assays (QIAGEN, Hilden, Germany) were used to detect human NLRP3, PYCARD, B2M. All other primers were from Biomers $\mathrm{GmbH}$, Germany. Mouse $1 l 1 b 5^{\prime}$-TGAAATGCCACCTTTTGACA-3' and $5^{\prime}$-AGCTTCTCCACAGCCACAAT- ${ }^{\prime}$, mouse $I l 18$ 5'-GGCTGCCATGTCAGAAGACT- ${ }^{\prime}$ ' and 5'-GTGAAGTCGGCCAAAGTTGT-3', mouse Nlrp3 $5^{\prime}$-ATTGCTGTGTGTGGGACTGA-3' and 5'-AACCAATGCGAGATCCTGAC-3', mouse Pycard $5^{\prime}$-ACATGGGCTTACAGGAGCTG-3' ${ }^{\prime}$ and

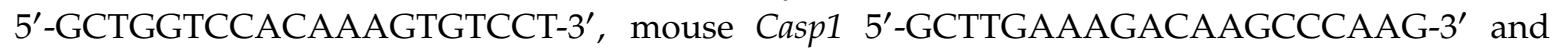
5'-GGCCTTCTTAATGCCATCAT-3', mouse Rsp27a $5^{\prime}$-GACCCTTACGGGGAAAACCAT-`3 and 5'-AGACAAAGTCCGGCCATCTTC-3' , human IL1B 5' 5 $^{\prime}$-TTCGACACATGGGATAACGAGG-3' and 5'-TTTTTGCTGTGAGTCCCGGAG-3' and human TNFA 5'-GAGGCCAAGCCCTGGTATG-3' ${ }^{\prime}$ and $5^{\prime}$-CGGGCCGATTGATCTCAGC-3'. Relative mRNA expression was calculated using either the CFX-Manager ${ }^{\mathrm{TM}}$ v3.2 software (Bio-Rad Laboratories) or the QuantStudio ${ }^{\mathrm{TM}}$ Design and Analysis software v1.5 (Applied Biosystems) using the $\Delta \Delta C_{t}$ method and normalized to either B2M (human) or Rps27a (mouse) as housekeeping genes.

\subsection{Cytokine Measurements}

To determine cytokine levels in cell culture supernatants human IL-1 $\beta$, and TNF- $\alpha$ or murine IL-1 $\beta$, IL-, IL-10, IL-23 (p19/p40), TNF- $\alpha$ and CCL5 Cytometric Bead Array Flex Sets (BD Biosciences, Franklin Lakes, NJ, USA) were used. Samples were acquired with a LSRII/Fortessa flow cytometer (BD Biosciences) and data were analyzed using BD Biosciences FCAP software (V3.0).

\subsection{Macrophage Culturing and Stimulation}

Primary human monocytes (PBMCs) were isolated from buffy coats of anonymous healthy donors obtained from DRK Blutspendedienst (Baden-Würtemberg-Hessen, Frankfurt, Germany) using Ficoll-Hypaque gradients (PAA Laboratories, Cölbe, Hessen, Germany). Cells were washed twice with PBS and plated onto high-adherence culture dishes (Sarstedt, Nümbrecht, Germany). After culturing PBMCs for $1 \mathrm{~h}$ in RPMI 1640 media containing with $100 \mathrm{U} / \mathrm{mL}$ penicillin and $100 \mu \mathrm{g} / \mathrm{mL}$ streptomycin, non-adherent cells were washed away, and remaining monocytes were cultured in media containing $5 \%$ AB-positive human serum for 7 days to allow the differentiation towards macrophages.

Bone marrow was isolated from tibia and femur of different mice strains described in the text and $4 \times 10^{6}$ bone marrow cells were plated in a 6-well plate in each well and were incubated in RPMI 1640 containing 10\% FCS, $100 \mathrm{U} / \mathrm{mL}$ penicillin, $100 \mu \mathrm{g} / \mathrm{mL}$ streptomycin. For differentiation into macrophages, cells were cultured in the presence of $20 \mathrm{ng} / \mathrm{mL} \mathrm{M-CSF}$ and $20 \mathrm{ng} / \mathrm{mL}$ GM-CSF 
(ImmunoTools, Friesoythe, Germany) for 7 days. Medium was replaced every second days and differentiated bone marrow-derived macrophages were stimulated with 10-100 ng/mL of LPS in combination with various stimuli described in figure legends for various time points.

\subsection{Analysis of Publicly Available Datasets of Gene Expression in Renal Cell Carcinoma and Psoriasis}

Publicly available datasets comprising 535 tumor samples and 72 control tissues of clear cell renal cell carcinoma patients [47] were obtained from TCGA-KIRC project [47] via Genomic Data Commons Data Portal [48] and analyzed by ENCORI Pan-Cancer Analysis Platform. Gene Expression Omnibus (GEO) datasets comprising 92 psoriatic and 82 normal skin samples (GSE54456) were downloaded and analyzed either via GEO2R [98] or GDSBrowser [99]. Expression profiles of S1P metabolizing enzymes along with NLRP3 inflammasome components and NF- $\mathrm{kB}$ target genes were further analyzed and plotted using GraphPad Prism v8.

\subsection{Statistical analysis}

All data are presented as mean values \pm SEM of at least two independent experiments. Statistical analyses were performed in GraphPad Prism $v .6$ using one-sample $t$-test, two-tailed Student's $t$-test, two-way ANOVA with Sidak correction with two-tailed $p$ values as indicated in the figure legends. Asterisks indicate significant differences between different groups $\left({ }^{*} p<0.05,{ }^{* *} p<0.01\right)$.

Author Contributions: Conceptualization, S.N.S.; methodology, S.N.S., A.W.; validation, S.N.S. and A.W.; formal analysis, S.N.S. and A.W.; investigation, S.S.N.; resources, B.B.; data curation, S.N.S.; writing—original draft preparation, S.N.S.; writing-review and editing, all authors; visualization, S.N.S. and B.B.; supervision, B.B.; project administration, B.B.; funding acquisition, B.B. All authors have read and agreed to the published version of the manuscript.

Funding: The study is supported by Deutsche Forschungsgemeinschaft SFB 1039 TP B04 (B.B.) and B06 (A.W.).

Acknowledgments: We thank Margarete Mijatovic and Gudrun Beyer for excellent technical assistance. We thank Prof. Josef Pfeilschifter, Goethe-University Frankfurt for Sphk1 and Sphk2 knockout mice. A part of results presented here are based upon data generated by the TCGA Research Network: https://www.cancer.gov/tcga and curated by ENCORI: The Encyclopedia of RNA Interactomes: http://starbase.sysu.edu.cn/index.php. The authors acknowledge the support of the Cardio-Pulmonary Institute (CPI), EXC 2026, Project ID: 390649896.

Conflicts of Interest: The authors declare no conflict of interest.

\section{Abbreviations}

$\begin{array}{ll}\text { NLRP3 } & \text { NACHT, LRR and PYD domains-containing Protein } 3 \\ \text { PYCARD } & \text { PYD And CARD Domain-Containing Protein } \\ \text { S1P } & \text { Sphingosine-1-phosphate } \\ \text { SPHK } & \text { Sphingosine Kinase } \\ \text { SGPL } & \text { S1P lyase } \\ \text { AlOH } & \text { Aluminum Hydroxide } \\ \text { WT } & \text { Wild type } \\ \text { KO } & \text { Knock out } \\ \text { IL } & \text { Interleukin } \\ \text { TNF } & \text { Tumor-necrosis factor } \\ \text { RCC } & \text { Renal cell carcinoma }\end{array}$

\section{References}

1. Sica, A.; Mantovani, A. Macrophage plasticity and polarization: In vivo veritas. J. Clin. Invest. 2012, 122, 787-795. [CrossRef]

2. Hanahan, D.; Weinberg, R.A. Hallmarks of cancer: The next generation. Cell 2011, 144, 646-674. [CrossRef]

3. Schroder, K.; Tschopp, J. The inflammasomes. Cell 2010, 140, 821-832. [CrossRef] 
4. Mariathasan, S.; Weiss, D.S.; Newton, K.; McBride, J.; O’Rourke, K.; Roose-Girma, M.; Lee, W.P.; Weinrauch, Y.; Monack, D.M.; Dixit, V.M. Cryopyrin activates the inflammasome in response to toxins and ATP. Nature 2006, 440, 228-232. [CrossRef]

5. Dostert, C.; Pétrilli, V.; Van Bruggen, R.; Steele, C.; Mossman, B.T.; Tschopp, J. Innate immune activation through Nalp3 inflammasome sensing of asbestos and silica. Science 2008, 320, 674-677. [CrossRef] [PubMed]

6. Martinon, F.; Pétrilli, V.; Mayor, A.; Tardivel, A.; Tschopp, J. Gout-associated uric acid crystals activate the NALP3 inflammasome. Nature 2006, 440, 237-241. [CrossRef]

7. Bauernfeind, F.G.; Horvath, G.; Stutz, A.; Alnemri, E.S.; MacDonald, K.; Speert, D.; Fernandes-Alnemri, T.; $\mathrm{Wu}$, J.; Monks, B.G.; Fitzgerald, K.A.; et al. Cutting edge: NF-kappaB activating pattern recognition and cytokine receptors license NLRP3 inflammasome activation by regulating NLRP3 expression. J. Immunol. 2009, 183, 787-791. [CrossRef]

8. Franchi, L.; Eigenbrod, T.; Núñez, G. Cutting edge: TNF-alpha mediates sensitization to ATP and silica via the NLRP3 inflammasome in the absence of microbial stimulation. J. Immunol. 2009, 183, 792-796. [CrossRef]

9. Juliana, C.; Fernandes-Alnemri, T.; Kang, S.; Farias, A.; Qin, F.; Alnemri, E.S. Non-transcriptional priming and deubiquitination regulate NLRP3 inflammasome activation. J. Biol. Chem. 2012, 287, 36617-36622. [CrossRef]

10. He, Y.; Hara, H.; Núñez, G. Mechanism and Regulation of NLRP3 Inflammasome Activation. Trends Biochem. Sci. 2016, 41, 1012-1021. [CrossRef]

11. Syed, S.N.; Jung, M.; Weigert, A.; Brüne, B. S1P Provokes Tumor Lymphangiogenesis via Macrophage-Derived Mediators Such as IL-1 $\beta$ or Lipocalin-2. Mediat. Inflamm. 2017, 2017, 7510496. [CrossRef] [PubMed]

12. Weichand, B.; Popp, R.; Dziumbla, S.; Mora, J.; Strack, E.; Elwakeel, E.; Frank, A.-C.; Scholich, K.; Pierre, S.; Syed, S.N.; et al. S1PR1 on tumor-associated macrophages promotes lymphangiogenesis and metastasis via NLRP3/IL-1ß. J. Exp. Med. 2017, 214, 2695-2713. [CrossRef] [PubMed]

13. Burow, P.; Klapperstück, M.; Markwardt, F. Activation of ATP secretion via volume-regulated anion channels by sphingosine-1-phosphate in RAW macrophages. Pflugers Arch. 2015, 467, 1215-1226. [CrossRef] [PubMed]

14. Zhao, S.; Gong, Z.; Zhou, J.; Tian, C.; Gao, Y.; Xu, C.; Chen, Y.; Cai, W.; Wu, J. Deoxycholic Acid Triggers NLRP3 Inflammasome Activation and Aggravates DSS-Induced Colitis in Mice. Front. Immunol. 2016, 7, 536. [CrossRef]

15. Skoura, A.; Michaud, J.; Im, D.-S.; Thangada, S.; Xiong, Y.; Smith, J.D.; Hla, T. Sphingosine-1-phosphate receptor-2 function in myeloid cells regulates vascular inflammation and atherosclerosis. Arterioscler. Thromb. Vasc. Biol. 2011, 31, 81-85. [CrossRef]

16. Nagahashi, M.; Ramachandran, S.; Kim, E.Y.; Allegood, J.C.; Rashid, O.M.; Yamada, A.; Zhao, R.; Milstien, S.; Zhou, H.; Spiegel, S.; et al. Sphingosine-1-phosphate produced by sphingosine kinase 1 promotes breast cancer progression by stimulating angiogenesis and lymphangiogenesis. Cancer Res. 2012, 72, 726-735. [CrossRef]

17. Weigert, A.; Olesch, C.; Brüne, B. Sphingosine-1-Phosphate and Macrophage Biology-How the Sphinx Tames the Big Eater. Front. Immunol. 2019, 10, 1706. [CrossRef]

18. Pyne, N.J.; El Buri, A.; Adams, D.R.; Pyne, S. Sphingosine 1-phosphate and cancer. Adv. Biol. Regul. 2018, 68, 97-106. [CrossRef]

19. Spiegel, S.; Milstien, S. The outs and the ins of sphingosine-1-phosphate in immunity. Nat. Rev. Immunol. 2011, 11, 403-415. [CrossRef]

20. Weigert, A.; Weichand, B.; Brune, B. S1P regulation of macrophage functions in the context of cancer. Anticancer Agents Med. Chem. 2011, 11, 818-829. [CrossRef]

21. Hait, N.C.; Allegood, J.; Maceyka, M.; Strub, G.M.; Harikumar, K.B.; Singh, S.K.; Luo, C.; Marmorstein, R.; Kordula, T.; Milstien, S.; et al. Regulation of histone acetylation in the nucleus by sphingosine-1-phosphate. Science 2009, 325, 1254-1257. [CrossRef] [PubMed]

22. Alvarez, S.E.; Harikumar, K.B.; Hait, N.C.; Allegood, J.; Strub, G.M.; Kim, E.Y.; Maceyka, M.; Jiang, H.; Luo, C.; Kordula, T.; et al. Sphingosine-1-phosphate is a missing cofactor for the E3 ubiquitin ligase TRAF2. Nature 2010, 465, 1084-1088. [CrossRef] [PubMed]

23. Mattie, M.; Brooker, G.; Spiegel, S. Sphingosine-1-phosphate, a putative second messenger, mobilizes calcium from internal stores via an inositol trisphosphate-independent pathway. J. Biol. Chem. 1994, 269, 3181-3188. [PubMed] 
24. Ghosh, T.K.; Bian, J.; Gill, D.L. Intracellular calcium release mediated by sphingosine derivatives generated in cells. Science 1990, 248, 1653-1656. [CrossRef] [PubMed]

25. Ghosh, T.K.; Bian, J.; Gill, D.L. Sphingosine 1-phosphate generated in the endoplasmic reticulum membrane activates release of stored calcium. J. Biol. Chem. 1994, 269, 22628-22635. [PubMed]

26. Ebrahimian, T.; Arfa, O.; Simeone, S.; Lemarié, C.A.; Lehoux, S.; Wassmann, S. Inhibition of four-and-a-half LIM domain protein-2 increases survival, migratory capacity, and paracrine function of human early outgrowth cells through activation of the sphingosine kinase-1 pathway: Implications for endothelial regeneration. Circ. Res. 2014, 114, 114-123. [CrossRef]

27. French, K.J.; Schrecengost, R.S.; Lee, B.D.; Zhuang, Y.; Smith, S.N.; Eberly, J.L.; Yun, J.K.; Smith, C.D. Discovery and evaluation of inhibitors of human sphingosine kinase. Cancer Res. 2003, 63, 5962-5969.

28. Gao, P.; Peterson, Y.K.; Smith, R.A.; Smith, C.D. Characterization of isoenzyme-selective inhibitors of human sphingosine kinases. PLoS ONE 2012, 7, e44543. [CrossRef]

29. Watson, D.G.; Tonelli, F.; Alossaimi, M.; Williamson, L.; Chan, E.; Gorshkova, I.; Berdyshev, E.; Bittman, R.; Pyne, N.J.; Pyne, S. The roles of sphingosine kinases 1 and 2 in regulating the Warburg effect in prostate cancer cells. Cell. Signal. 2013, 25, 1011-1017. [CrossRef]

30. Park, K.S.; Kim, M.-K.; Lee, H.Y.; Kim, S.D.; Lee, S.Y.; Kim, J.M.; Ryu, S.H.; Bae, Y.-S. S1P stimulates chemotactic migration and invasion in OVCAR3 ovarian cancer cells. Biochem. Biophys. Res. Commun. 2007, 356, 239-244. [CrossRef]

31. Broz, P.; Dixit, V.M. Inflammasomes: Mechanism of assembly, regulation and signalling. Nat. Rev. Immunol. 2016, 16, 407-420. [CrossRef] [PubMed]

32. Luheshi, N.M.; Giles, J.A.; Lopez-Castejon, G.; Brough, D. Sphingosine regulates the NLRP3-inflammasome and IL-1 $\beta$ release from macrophages. Eur. J. Immunol. 2012, 42, 716-725. [CrossRef] [PubMed]

33. Boomkamp, S.D.; Byun, H.-S.; Ubhi, S.; Jiang, H.-R.; Pyne, S.; Bittman, R.; Pyne, N.J. Effect of ether glycerol lipids on interleukin-1 $\beta$ release and experimental autoimmune encephalomyelitis. Chem. Phys. Lipids 2016, 194, 2-11. [CrossRef] [PubMed]

34. Habrukowich, C.; Han, D.K.; Le, A.; Rezaul, K.; Pan, W.; Ghosh, M.; Li, Z.; Dodge-Kafka, K.; Jiang, X.; Bittman, R.; et al. Sphingosine interaction with acidic leucine-rich nuclear phosphoprotein-32A (ANP32A) regulates PP2A activity and cyclooxygenase (COX)-2 expression in human endothelial cells. J. Biol. Chem. 2010, 285, 26825-26831. [CrossRef]

35. Muñoz-Planillo, R.; Kuffa, P.; Martínez-Colón, G.; Smith, B.L.; Rajendiran, T.M.; Núñez, G. K ${ }^{+}$efflux is the common trigger of NLRP3 inflammasome activation by bacterial toxins and particulate matter. Immunity 2013, 38, 1142-1153. [CrossRef]

36. Pétrilli, V.; Papin, S.; Dostert, C.; Mayor, A.; Martinon, F.; Tschopp, J. Activation of the NALP3 inflammasome is triggered by low intracellular potassium concentration. Cell Death Differ. 2007, 14, 1583-1589. [CrossRef]

37. Yang, D.; He, Y.; Muñoz-Planillo, R.; Liu, Q.; Núñez, G. Caspase-11 Requires the Pannexin-1 Channel and the Purinergic P2X7 Pore to Mediate Pyroptosis and Endotoxic Shock. Immunity 2015, 43, 923-932. [CrossRef]

38. Rühl, S.; Broz, P. Caspase-11 activates a canonical NLRP3 inflammasome by promoting K(+) efflux. Eur. J. Immunol. 2015, 45, 2927-2936. [CrossRef]

39. Schroder, K.; Irvine, K.M.; Taylor, M.S.; Bokil, N.J.; Le Cao, K.-A.; Masterman, K.-A.; Labzin, L.I.; Semple, C.A.; Kapetanovic, R.; Fairbairn, L.; et al. Conservation and divergence in Toll-like receptor 4-regulated gene expression in primary human versus mouse macrophages. Proc. Natl. Acad. Sci. USA 2012, 109, E944-E953. [CrossRef]

40. Mestas, J.; Hughes, C.C.W. Of mice and not men: Differences between mouse and human immunology. J. Immunol. 2004, 172, 2731-2738. [CrossRef]

41. Groß, C.J.; Mishra, R.; Schneider, K.S.; Médard, G.; Wettmarshausen, J.; Dittlein, D.C.; Shi, H.; Gorka, O.; Koenig, P.-A.; Fromm, S.; et al. K+ Efflux-Independent NLRP3 Inflammasome Activation by Small Molecules Targeting Mitochondria. Immunity 2016, 45, 761-773. [CrossRef] [PubMed]

42. Kanneganti, T.-D.; Ozören, N.; Body-Malapel, M.; Amer, A.; Park, J.-H.; Franchi, L.; Whitfield, J.; Barchet, W.; Colonna, M.; Vandenabeele, P.; et al. Bacterial RNA and small antiviral compounds activate caspase-1 through cryopyrin/Nalp3. Nature 2006, 440, 233-236. [CrossRef] [PubMed]

43. Stratis, A.; Pasparakis, M.; Rupec, R.A.; Markur, D.; Hartmann, K.; Scharffetter-Kochanek, K.; Peters, T.; Van Rooijen, N.; Krieg, T.; Haase, I. Pathogenic role for skin macrophages in a mouse model of 
keratinocyte-induced psoriasis-like skin inflammation. J. Clin. Invest. 2006, 116, 2094-2104. [CrossRef] [PubMed]

44. Noy, R.; Pollard, J.W. Tumor-associated macrophages: From mechanisms to therapy. Immunity 2014, 41, 49-61. [CrossRef] [PubMed]

45. Pal, S.K.; Drabkin, H.A.; Reeves, J.A.; Hainsworth, J.D.; Hazel, S.E.; Paggiarino, D.A.; Wojciak, J.; Woodnutt, G.; Bhatt, R.S. A phase 2 study of the sphingosine-1-phosphate antibody sonepcizumab in patients with metastatic renal cell carcinoma. Cancer 2017, 123, 576-582. [CrossRef]

46. Syed, S.N.; Raue, R.; Weigert, A.; Knethen, A.; Von Brüne, B. Macrophage S1PR1 Signaling Alters Angiogenesis and Lymphangiogenesis During Skin Inflammation. Cells 2019, 8. [CrossRef]

47. Cancer Genome Atlas Research Network. Comprehensive molecular characterization of clear cell renal cell carcinoma. Nature 2013, 499, 43-49. [CrossRef]

48. Genomic Data Commons. Available online: https://portal.gdc.cancer.gov/.

49. Li, J.-H.; Liu, S.; Zhou, H.; Qu, L.-H.; Yang, J.-H. starBase v2.0: Decoding miRNA-ceRNA, miRNA-ncRNA and protein-RNA interaction networks from large-scale CLIP-Seq data. Nucleic Acids Res. 2014, 42, D92-D97. [CrossRef]

50. Tsoi, L.C.; Iyer, M.K.; Stuart, P.E.; Swindell, W.R.; Gudjonsson, J.E.; Tejasvi, T.; Sarkar, M.K.; Li, B.; Ding, J.; Voorhees, J.J.; et al. Analysis of long non-coding RNAs highlights tissue-specific expression patterns and epigenetic profiles in normal and psoriatic skin. Genome Biol. 2015, 16, 24. [CrossRef]

51. Li, B.; Tsoi, L.C.; Swindell, W.R.; Gudjonsson, J.E.; Tejasvi, T.; Johnston, A.; Ding, J.; Stuart, P.E.; Xing, X.; Kochkodan, J.J.; et al. Transcriptome analysis of psoriasis in a large case-control sample: RNA-seq provides insights into disease mechanisms. J. Invest. Dermatol. 2014, 134, 1828-1838. [CrossRef]

52. Taha, T.A.; Hannun, Y.A.; Obeid, L.M. Sphingosine kinase: Biochemical and cellular regulation and role in disease. J. Biochem. Mol. Biol. 2006, 39, 113-131. [CrossRef] [PubMed]

53. Spiegel, S.; Milstien, S. Sphingosine-1-phosphate: Signaling inside and out. FEBS Lett. 2000, 476, 55-57. [CrossRef]

54. Weigert, A.; Weis, N.; Brüne, B. Regulation of macrophage function by sphingosine-1-phosphate. Immunobiology 2009, 214, 748-760. [CrossRef] [PubMed]

55. Hanson, M.A.; Roth, C.B.; Jo, E.; Griffith, M.T.; Scott, F.L.; Reinhart, G.; Desale, H.; Clemons, B.; Cahalan, S.M.; Schuerer, S.C.; et al. Crystal structure of a lipid G protein-coupled receptor. Science 2012, 335, 851-855. [CrossRef]

56. Xia, P.; Wang, L.; Moretti, P.A.B.; Albanese, N.; Chai, F.; Pitson, S.M.; D'Andrea, R.J.; Gamble, J.R.; Vadas, M.A. Sphingosine kinase interacts with TRAF2 and dissects tumor necrosis factor-alpha signaling. J. Biol. Chem. 2002, 277, 7996-8003. [CrossRef]

57. Huang, K.; Huang, J.; Chen, C.; Hao, J.; Wang, S.; Huang, J.; Liu, P.; Huang, H. AP-1 regulates sphingosine kinase 1 expression in a positive feedback manner in glomerular mesangial cells exposed to high glucose. Cell Signal. 2014, 26, 629-638. [CrossRef]

58. Wu, W.; Mosteller, R.D.; Broek, D. Sphingosine kinase protects lipopolysaccharide-activated macrophages from apoptosis. Mol. Cell. Biol. 2004, 24, 7359-7369. [CrossRef]

59. Weigert, A.; Johann, A.M.; Von Knethen, A.; Schmidt, H.; Geisslinger, G.; Brüne, B. Apoptotic cells promote macrophage survival by releasing the antiapoptotic mediator sphingosine-1-phosphate. Blood 2006, 108, 1635-1642. [CrossRef]

60. Han, S.; Lear, T.B.; Jerome, J.A.; Rajbhandari, S.; Snavely, C.A.; Gulick, D.L.; Gibson, K.F.; Zou, C.; Chen, B.B.; Mallampalli, R.K. Lipopolysaccharide Primes the NALP3 Inflammasome by Inhibiting Its Ubiquitination and Degradation Mediated by the SCFFBXL2 E3 Ligase. J. Biol. Chem. 2015, 290, 18124-18133. [CrossRef]

61. Maceyka, M.; Sankala, H.; Hait, N.C.; Le Stunff, H.; Liu, H.; Toman, R.; Collier, C.; Zhang, M.; Satin, L.S.; Merrill, A.H.; et al. SphK1 and SphK2, sphingosine kinase isoenzymes with opposing functions in sphingolipid metabolism. J. Biol. Chem. 2005, 280, 37118-37129. [CrossRef]

62. Maceyka, M.; Harikumar, K.B.; Milstien, S.; Spiegel, S. Sphingosine-1-phosphate signaling and its role in disease. Trends Cell Biol. 2012, 22, 50-60. [CrossRef] [PubMed]

63. Chipuk, J.E.; McStay, G.P.; Bharti, A.; Kuwana, T.; Clarke, C.J.; Siskind, L.J.; Obeid, L.M.; Green, D.R. Sphingolipid metabolism cooperates with BAK and BAX to promote the mitochondrial pathway of apoptosis. Cell 2012, 148, 988-1000. [CrossRef] [PubMed] 
64. Wang, Q.; He, Z.; Huang, M.; Liu, T.; Wang, Y.; Xu, H.; Duan, H.; Ma, P.; Zhang, L.; Zamvil, S.S.; et al. Vascular niche IL-6 induces alternative macrophage activation in glioblastoma through HIF-2 $\alpha$. Nat. Commun. 2018, 9, 559. [CrossRef] [PubMed]

65. Roca, H.; Varsos, Z.S.; Sud, S.; Craig, M.J.; Ying, C.; Pienta, K.J. CCL2 and interleukin-6 promote survival of human $\mathrm{CD} 11 \mathrm{~b}+$ peripheral blood mononuclear cells and induce M2-type macrophage polarization. J. Biol. Chem. 2009, 284, 34342-34354. [CrossRef]

66. Meng, F.; Yamagiwa, Y.; Ueno, Y.; Patel, T. Over-expression of interleukin-6 enhances cell survival and transformed cell growth in human malignant cholangiocytes. J. Hepatol. 2006, 44, 1055-1065. [CrossRef]

67. Weigert, A.; Von Knethen, A.; Thomas, D.; Faria, I.; Namgaladze, D.; Zezina, E.; Fuhrmann, D.; Petcherski, A.; zu Heringdorf, D.M.; Radeke, H.H.; et al. Sphingosine kinase 2 is a negative regulator of inflammatory macrophage activation. Biochim. Biophys. Acta Mol. Cell Biol. Lipids 2019, 1864, 1235-1246. [CrossRef] [PubMed]

68. Kayagaki, N.; Wong, M.T.; Stowe, I.B.; Ramani, S.R.; Gonzalez, L.C.; Akashi-Takamura, S.; Miyake, K.; Zhang, J.; Lee, W.P.; Muszyński, A.; et al. Noncanonical inflammasome activation by intracellular LPS independent of TLR4. Science 2013, 341, 1246-1249. [CrossRef] [PubMed]

69. Hagar, J.A.; Powell, D.A.; Aachoui, Y.; Ernst, R.K.; Miao, E.A. Cytoplasmic LPS activates caspase-11: Implications in TLR4-independent endotoxic shock. Science 2013, 341, 1250-1253. [CrossRef]

70. Wang, H.; Mao, L.; Meng, G. The NLRP3 inflammasome activation in human or mouse cells, sensitivity causes puzzle. Protein Cell 2013, 4, 565-568. [CrossRef]

71. Allende, M.L.; Sasaki, T.; Kawai, H.; Olivera, A.; Mi, Y.; Van Echten-Deckert, G.; Hajdu, R.; Rosenbach, M.; Keohane, C.A.; Mandala, S.; et al. Mice deficient in sphingosine kinase 1 are rendered lymphopenic by FTY720. J. Biol. Chem. 2004, 279, 52487-52492. [CrossRef]

72. Mizugishi, K.; Yamashita, T.; Olivera, A.; Miller, G.F.; Spiegel, S.; Proia, R.L. Essential role for sphingosine kinases in neural and vascular development. Mol. Cell. Biol. 2005, 25, 11113-11121. [CrossRef] [PubMed]

73. Xiong, Y.; Lee, H.J.; Mariko, B.; Lu, Y.-C.; Dannenberg, A.J.; Haka, A.S.; Maxfield, F.R.; Camerer, E.; Proia, R.L.; Hla, T. Sphingosine kinases are not required for inflammatory responses in macrophages. J. Biol. Chem. 2013, 288, 32563-32573. [CrossRef] [PubMed]

74. Mandala, S.; Hajdu, R.; Bergstrom, J.; Quackenbush, E.; Xie, J.; Milligan, J.; Thornton, R.; Shei, G.-J.; Card, D.; Keohane, C.; et al. Alteration of lymphocyte trafficking by sphingosine-1-phosphate receptor agonists. Science 2002, 296, 346-349. [CrossRef] [PubMed]

75. Hla, T.; Brinkmann, V. Sphingosine 1-phosphate (S1P): Physiology and the effects of S1P receptor modulation. Neurology 2011, 76, S3-S8. [CrossRef]

76. Tonelli, F.; Lim, K.G.; Loveridge, C.; Long, J.; Pitson, S.M.; Tigyi, G.; Bittman, R.; Pyne, S.; Pyne, N.J. FTY720 and (S)-FTY720 vinylphosphonate inhibit sphingosine kinase 1 and promote its proteasomal degradation in human pulmonary artery smooth muscle, breast cancer and androgen-independent prostate cancer cells. Cell Signal. 2010, 22, 1536-1542. [CrossRef]

77. Jeffery, D.R.; Markowitz, C.E.; Reder, A.T.; Weinstock-Guttman, B.; Tobias, K. Fingolimod for the treatment of relapsing multiple sclerosis. Expert Rev. Neurother. 2011, 11, 165-183. [CrossRef]

78. Pelletier, D.; Hafler, D.A. Fingolimod for multiple sclerosis. N. Engl. J. Med. 2012, 366, 339-347. [CrossRef]

79. Baker, D.A.; Eudaly, J.; Smith, C.D.; Obeid, L.M.; Gilkeson, G.S. Impact of sphingosine kinase 2 deficiency on the development of TNF-alpha-induced inflammatory arthritis. Rheumatol. Int. 2013, 33, 2677-2681. [CrossRef]

80. Zhu, Z.-A.; Zhu, Z.-Q.; Cai, H.-X.; Liu, Y. Reversion of multidrug resistance by SKI-II in SGC7901/DDP cells and exploration of underlying mechanisms. Asian Pac. J. Cancer Prev. 2012, 13, 625-631. [CrossRef]

81. Frank, A.-C.; Ebersberger, S.; Fink, A.F.; Lampe, S.; Weigert, A.; Schmid, T.; Ebersberger, I.; Syed, S.N.; Brüne, B. Apoptotic tumor cell-derived microRNA-375 uses CD36 to alter the tumor-associated macrophage phenotype. Nat. Commun. 2019, 10, 1135. [CrossRef]

82. Chiba, Y.; Takeuchi, H.; Sakai, H.; Misawa, M. SKI-II, an inhibitor of sphingosine kinase, ameliorates antigen-induced bronchial smooth muscle hyperresponsiveness, but not airway inflammation, in mice. J. Pharmacol. Sci. 2010, 114, 304-310. [CrossRef]

83. Vandanmagsar, B.; Youm, Y.-H.; Ravussin, A.; Galgani, J.E.; Stadler, K.; Mynatt, R.L.; Ravussin, E.; Stephens, J.M.; Dixit, V.D. The NLRP3 inflammasome instigates obesity-induced inflammation and insulin resistance. Nat. Med. 2011, 17, 179-188. [CrossRef] [PubMed] 
84. Youm, Y.-H.; Grant, R.W.; McCabe, L.R.; Albarado, D.C.; Nguyen, K.Y.; Ravussin, A.; Pistell, P.; Newman, S.; Carter, R.; Laque, A.; et al. Canonical Nlrp3 inflammasome links systemic low-grade inflammation to functional decline in aging. Cell Metab. 2013, 18, 519-532. [CrossRef]

85. Wang, H.; Peters, T.; Kess, D.; Sindrilaru, A.; Oreshkova, T.; Van Rooijen, N.; Stratis, A.; Renkl, A.C.; Sunderkötter, C.; Wlaschek, M.; et al. Activated macrophages are essential in a murine model for T cell-mediated chronic psoriasiform skin inflammation. J. Clin. Invest. 2006, 116, 2105-2114. [CrossRef] [PubMed]

86. Chittezhath, M.; Dhillon, M.K.; Lim, J.Y.; Laoui, D.; Shalova, I.N.; Teo, Y.L.; Chen, J.; Kamaraj, R.; Raman, L.; Lum, J.; et al. Molecular profiling reveals a tumor-promoting phenotype of monocytes and macrophages in human cancer progression. Immunity 2014, 41, 815-829. [CrossRef] [PubMed]

87. Oskouian, B.; Sooriyakumaran, P.; Borowsky, A.D.; Crans, A.; Dillard-Telm, L.; Tam, Y.Y.; Bandhuvula, P.; Saba, J.D. Sphingosine-1-phosphate lyase potentiates apoptosis via p53- and p38-dependent pathways and is down-regulated in colon cancer. Proc. Natl. Acad. Sci. USA 2006, 103, 17384-17389. [CrossRef] [PubMed]

88. Ramaswamy, S.; Ross, K.N.; Lander, E.S.; Golub, T.R. A molecular signature of metastasis in primary solid tumors. Nat. Genet. 2003, 33, 49-54. [CrossRef] [PubMed]

89. Hibbs, K.; Skubitz, K.M.; Pambuccian, S.E.; Casey, R.C.; Burleson, K.M.; Oegema, T.R.; Thiele, J.J.; Grindle, S.M.; Bliss, R.L.; Skubitz, A.P.N. Differential Gene Expression in Ovarian Carcinoma. Am. J. Pathol. 2004, 165, 397-414. [CrossRef]

90. Bernardini, M.; Lee, C.-H.; Beheshti, B.; Prasad, M.; Albert, M.; Marrano, P.; Begley, H.; Shaw, P.; Covens, A.; Murphy, J.; et al. High-resolution mapping of genomic imbalance and identification of gene expression profiles associated with differential chemotherapy response in serous epithelial ovarian cancer. Neoplasia 2005, 7, 603-613. [CrossRef]

91. Okada, T.; Ding, G.; Sonoda, H.; Kajimoto, T.; Haga, Y.; Khosrowbeygi, A.; Gao, S.; Miwa, N.; Jahangeer, S.; Nakamura, S.-I. Involvement of N-terminal-extended form of sphingosine kinase 2 in serum-dependent regulation of cell proliferation and apoptosis. J. Biol. Chem. 2005, 280, 36318-36325. [CrossRef]

92. Xu, Y.; Dong, B.; Wang, J.; Zhang, J.; Xue, W.; Huang, Y. Sphingosine kinase 1 overexpression contributes to sunitinib resistance in clear cell renal cell carcinoma. Oncoimmunology 2018, 7, e1502130. [CrossRef]

93. Gao, M.-Q.; Gao, H.; Han, M.; Liu, K.-L.; Peng, J.-J.; Han, Y.-T. Hispidulin suppresses tumor growth and metastasis in renal cell carcinoma by modulating ceramide-sphingosine 1-phosphate rheostat. Am. J. Cancer Res. 2017, 7, 1501-1514. [PubMed]

94. Smale, S.T. Hierarchies of NF-кB target-gene regulation. Nat. Immunol. 2011, 12, 689-694. [CrossRef] [PubMed]

95. Schröder, M.; Richter, C.; Juan, M.H.S.; Maltusch, K.; Giegold, O.; Quintini, G.; Pfeilschifter, J.M.; Huwiler, A.; Radeke, H.H. The sphingosine kinase 1 and S1P1 axis specifically counteracts LPS-induced IL-12p70 production in immune cells of the spleen. Mol. Immunol. 2011, 48, 1139-1148. [CrossRef] [PubMed]

96. Pushparaj, P.N.; Manikandan, J.; Tay, H.K.; H’ng, S.C.; Kumar, S.D.; Pfeilschifter, J.; Huwiler, A.; Melendez, A.J. Sphingosine kinase 1 is pivotal for Fc epsilon RI-mediated mast cell signaling and functional responses in vitro and in vivo. J. Immunol. 2009, 183, 221-227. [CrossRef] [PubMed]

97. Coldewey, S.M.; Benetti, E.; Collino, M.; Pfeilschifter, J.; Sponholz, C.; Bauer, M.; Huwiler, A.; Thiemermann, C. Elevation of serum sphingosine-1-phosphate attenuates impaired cardiac function in experimental sepsis. Sci. Rep. 2016, 6, 27594. [CrossRef] [PubMed]

98. GEO2R. Available online: https://www.ncbi.nlm.nih.gov/geo/geo2r/.

99. GDSBrowser. Available online: https://www.ncbi.nlm.nih.gov/sites/GDSbrowser/.

(C) 2020 by the authors. Licensee MDPI, Basel, Switzerland. This article is an open access article distributed under the terms and conditions of the Creative Commons Attribution (CC BY) license (http://creativecommons.org/licenses/by/4.0/). 